\title{
La computadora e Internet como estrategia de inclusión social en el imaginario de los pobres.
}

\author{
Rosalía Winocur \\ winocurecorreo.xoc.uam.mx \\ Universidad Autónoma Metropolitana
}

\section{Introducción}

En México, el imaginario sobre las nuevas tecnologías, se construye sobre la abrumadora realidad de que más del $80 \%$ de sus habitantes no tiene acceso a una computadora, y más del $90 \%$ a Internet. Según el último censo de población realizado en el año 2000, sólo el 9\% de los hogares poseía una computadora, de los cuales sólo el 53\% tenía acceso a Internet (INEGI, 2001), y esta cifra se concentra básicamente en las grandes urbes. Otra encuesta realizada por INEGI, señala que únicamente el $16,6 \%$ de la población usa computadora dentro y fuera del hogar [2]. Estos datos determinan de manera contundente que el uso de este medio es aún muy restringido y que básicamente se concentra en la educación media y superior, y en el sector de la administración pública y privada de las grandes ciudades. Respecto a los jóvenes, según una encuesta de Unicef sólo 14\% de adolescentes mexicanos tiene una computadora en la casa. No obstante hay computadoras en el $70 \%$ de las escuelas secundarias públicas, en el $10 \%$ de las primarias a cargo del Estado [3], y en la creciente proliferación de cafés Internet distribuidos en varias ciudades y poblados del territorio. La mayoría de los jóvenes que están en algún sistema escolarizado, independientemente de su condición social, tienen potencialmente la posibilidad de conectarse a Internet en su casa, la escuela, la universidad, o en un café Internet. Los sistemas escolarizados y las exigencias de capacitación que plantean los empleos en las ciudades y poblaciones de mediano desarrollo, crean y facilitan ámbitos de socialización informáticos que fundamentalmente aprovechan los adolescentes y jóvenes. No obstante, es necesario señalar que el hecho de que muchos jóvenes de los sectores populares tengan acceso a las computadoras, no garantiza que éste se produzca en igualdad de condiciones ni que la experiencia en términos de apropiación socio-cultural sea similar: "Algunos jóvenes, aprovisionados en un recorrido previo por el circuito mediático en el que se mueven con fluidez, llegan hábiles y preparados para transitar en la red y, en una fusión total con la máquina, se vuelven los más diestros navegantes; otros jóvenes, y la mayoría de sus maestros, por su parte, extraviados entre la dificultad técnica, el poco entrenamiento en ámbitos tecnológicos y un bajo equipamiento en su capital cultural, naufragan con prontitud, facilidad y angustia" (Cabrera Paz, 2001:40).

\section{La computadora como recurso de movilidad social en el imaginario popular}

La cuestión del acceso a las nuevas tecnologías de la información se ha instalado en el imaginario de la mayoría de los jóvenes y de sus familias, particularmente en el ámbito urbano e independientemente de su condición socio-cultural, como una necesidad indiscutible, que día a día profundiza más el abismo entre quienes acceden y quienes no. Nuestra investigación [4] nos permitió constatar claramente que esta necesidad se presenta asociada a la preocupación de que si no se posee una computadora, en el futuro van a quedar marginados de todos sus beneficios, lo que a su vez va a marcar una profunda diferenciación social entre los que tienen acceso y los que no lo tienen: “...si los niños no tienen (una computadora) van a tener más problema, pues en la escuela van a saber menos que los que si tienen..." (Ama de casa, 43 años, primaria). Lo cual evidencia un temor a que la tecnología en general y la computadora en particular, se conviertan en un factor más de exclusión social: "Pues así como veo la vida yo pienso que el que no tenga una computadora va a ser como sino 
tuviera una mano, porque yo pienso que más adelante ya nadie va a ser nadie sino tienen una computadora." (Ama de casa, 40 años, primaria).

Independientemente de la posibilidad económica de adquirir una computadora o de conectarse a Internet, el habitus (Bourdieu, 1988), genera diversas formas de apropiación de la tecnología, facilitando o entorpeciendo su incorporación en el ámbito doméstico. Esto es evidente en la clara percepción de que el problema del acceso no se resuelve sólo con tener el aparato en casa, la condición para poder utilizarla y los probables beneficios que de ella se obtengan, dependen de que, en las condiciones de existencia y reproducción del capital cultural de cada grupo, se vuelva "socialmente necesaria" (Ford, 1999:159). En la siguiente cita podemos advertir que nuestro entrevistado no percibe ninguna ventaja en la computadora para su propio desempeño social y productivo, sin embargo entiende la importancia que tiene para "los otros" que si tienen los "conocimientos" para poder aprovecharla: "La computadora para algunos es algo muy importante para el trabajo, para la escuela, pero para mí no es nada importante porque no tengo conocimientos" (Despachador, 63 años, primaria). La representación de la exclusión está claramente asociada a las diferencias que se perciben en el capital cultural no sólo entre clases sociales sino también entre dos generaciones, una sin estudios y otra con estudios: “(...) si yo tuviera una computadora, ni la voy a saber manejar, la podría manejar, por decir, el muchacho que ha estudiado... el hecho de yo que tenga una computadora no significa que yo venga y pueda sacar información de ella, exclusivamente el que la sabe manejar" (Ama de casa, primaria, 42 años). De ahí, que en el caso de San Lorenzo Chimalpa, la computadora se haya instalado como una necesidad proyectada hacia los jóvenes y hacia los hijos, en la medida que siguen siendo depositarios de las aspiraciones de progreso y movilidad social[5]. En el siguiente ejemplo es interesante comprobar como la iniciación temprana del hijo en el manejo de la computadora marca un salto cualitativo respecto de su madre, quien a pesar de que ser muy joven y de haber recibido clases en la secundaria tuvo dificultades evidentes para apropiarse de la tecnología "a mí me enseñaban comandos, archivos y nunca lo pude entender pero mi hijo sí, luego me dice: "Mira mamá es que ya me enseñaron a prenderla, nos enseñaron a dibujar y mamá se le aprieta no se qué", y le digo “¿tú porque sí le entiendes?” (25 años, secundaria, ama de casa). El núcleo central de la representación que organiza y confiere sentido a esta idea, es que el origen de la desigualdad cultural no está en la desigual distribución de la riqueza, sino de la inteligencia y del conocimiento: "Es que a mí no me entró pero, a mí se me hace que la gente que usa la computadora es una gente muy inteligente porque le haya pero yo no." (Juana, 25 años, secundaria, comerciante. En el ejemplo siguiente se observa cómo se expresa esta representación en el mito sobre el origen de las computadoras, donde la imagen dominante es la de un "creador" solitario, hombre y dotado de una inteligencia privilegiada.... "Pues yo me imagino que fue una persona que tuvo mucha cabeza para el estudio, que era muy listo y que no hacia otra cosa sino estudiar y estar todo el día con los libros, porque pues, imagínese, para inventar un aparato tan grande como ese pues yo creo que fue alguien muy preparado" (mujer, 56 años, primaria, atiende un puesto en el mercado). Consecuentemente, la representación de la superación de la pobreza y la desigualdad de oportunidades está fuertemente asociada a la posibilidad de acceso al conocimiento, donde la computadora se habría convertido en una bisagra fundamental[6], no sólo porque se asocia con la educación, sino porque en la representación de sus poderes, su uso posibilitaría una transferencia de las cualidades del "creador" al usuario: inteligencia y poder para cambiar el destino propio y ajeno.

Asimismo, las familias que experimentan un grado creciente de frustración respecto a las posibilidades reales de "triunfar" con la fórmula tradicional del progreso: educación es igual a movilidad social, empiezan a visualizar en la computadora un atajo a los costosos y largos ciclos de la educación media y superior: “(...)yo tengo un primo que hizo un curso de capturista de datos y le agarró a la computadora, tuvo buen trabajo, estuvo en varias empresas, pero después él se sentía muy volado y decía que era ingeniero... ni siquiera acabó la vocacional" (49 años, secundaria, campesino). Esta representación se expresa de diversos modos, uno es la creencia de que el principal beneficio de la tecnología es que facilita las exigencias escolares y allana el camino hacia el éxito: “(...) ya no tienes que estar leyendo, ya no tienes que estar hojeando libros, que nada más aprietas un botón y ya aparece, se puede decir que, un resumen de un libro ya lo puedes encontrar en la computadora y no 
estar leyendo todo el libro." (Auxiliar de cocina, 24 años, primaria).Y es desde ese lugar que los hijos desde muy pequeños presionan en sus hogares para que sus padres incorporen dentro de sus prioridades de consumo, la compra de una computadora. La necesidad se plantea en términos de desventajas y de marginación, y así se lo transmiten a sus padres: si no tengo la computadora no sólo no voy a gozar de sus ventajas sino que voy a quedar fuera de lo que socialmente se ha vuelto significativo en términos de acceso al conocimiento, prestigio, placer, visibilidad, competitividad, reducción de complejidad y oportunidades de desarrollo: “(...) ahora sí que en el tiempo que estamos deben de saber estudiar, manejar aparatos, lo que es computadora, la Internet, máquinas de escribir y todo eso, porque pues ahora sí que tampoco quiero que mis hijos se queden como yo hasta la secundaria y namás con eso... ya para encontrar un trabajo está muy difícil, ya te piden papeles, qué carrera sabes, qué es lo que sabes hacer, y pues más que nada por eso sí me gustaría tener eso o aprender...., porque pues ahora sí que yo al menos, como me doy cuenta, como que se les facilitan más las cosas." (Obrero, 28 años, primaria).

Los jóvenes que tienen acceso a una computadora en la escuela o en los cafés Internet van socializando en el imaginario de la familia, los amigos y los vecinos sus usos y posibilidades y legitimando un discurso acerca de la necesidad de incorporar un aparato a corto, mediano o largo plazo, particularmente vinculado a nuevas exigencias escolares y a su capacidad de simplificar las labores escolares: "Yo creo que aunque uno no quiera, pues en algún momento la tenemos que comprar porque cada día se las exigen más en la escuela. Me doy cuenta con mis sobrinos que estudian la secundaria y otros la prepa, siempre tienen que ir a Chalco para hacer sus tareas en la computadora y dicen que les sale caro. Para facilitarle las cosas a Marlene yo creo que si la compraríamos y pues tendríamos que empezar ahorrar desde ahorita." (30 años, secundaria, ama de casa).

\section{La escuela como instancia de legitimación de la necesidad de incorporar las nuevas tecnologías}

Si bien los jóvenes contribuyen de manera significativa a generar la necesidad de incorporar la computadora e Internet en el seno del hogar, la escuela tiene un papel fundamental en la legitimación y la socialización de sus usos y posibilidades. La escuela, sin lugar, a dudas es la responsable de reforzar la necesidad de su adquisición en el imaginario de las familias populares para no quedar rezagado en lo que se percibe como una ventaja en el desempeño y el rendimiento educativo: “:(...)ya he platicado de eso con mi esposo y me dijo que si la vamos a tener que comprar porque pues Lupita a empezó a tener problemas por no tener el aparato." (Laura, 37 años, secundaria, ama de casa). Los maestros de secundaria y preparatoria, y, en algunos casos de la primaria, comienzan a solicitar a sus alumnos tareas que requieren el uso de la computadora, o se facilitan por su uso. Particularmente la elaboración de trabajos escritos a partir de la consulta de información en Internet. Los maestros no sólo premian las búsquedas en la red sino la presentación nítida y "limpia" de la tarea que muchas veces se aprecia más que los contenidos. Esta situación contribuye a que los padres comiencen a percibir en la computadora un recurso privilegiado para aumentar la competitividad de sus hijos en la escuela: "una vez mi hija me dijo que si nosotros también íbamos a comprar una porque una prima mía compró una y su hija que está en el mismo salón de Paulina lleva sus trabajos en la computadora y el maestro le pone puros dieces.” ( 41 años, primaria, ama de casa).

En el caso de San Lorenzo Chimalpa, sólo el 12\% de los hogares posee una computadora[7], sin embargo el $70 \%$ respondió que de tener, o reunir dinero, en un futuro próximo, si comprarían un aparato porque lo consideran necesario para facilitar la educación de sus hijos. Otro dato importante que refuerza la idea de que esta aspiración ya forma parte del imaginario popular, es que el $40 \%$ de los entrevistados había generado alguna clase de estrategia para acercar o facilitar el recurso tecnológico a sus hijos. En algunos casos, utilizando las redes familiares, o en otros, dando dinero a sus hijos para que renten computadoras en el centro de Chalco, distante unos 20 minutos del pueblo, o para pagar a alguien que les resuelva su tarea bajando información de Internet. La mayoría de los cafés Internet en el centro de Chalco tienen empleados que por encargo de los padres o de los niños, llevan a cabo las 
tareas escolares y/o apoyan a los niños para realizarlas. Primero buscan la información en Internet y luego la editan y le dan una presentación adecuada: "Pues a veces uno de mis sobrinos le ayuda porque el tiene computadora en su casa entonces Lupita (su hija) le llama por teléfono y el le trae los trabajos el fin de semana, pero cuando los trabajos son de un día para otro pues tenemos que ir a Chalco a rentar una o con un amigo de Lupita que vive por aquí cerca y que le presta la computadora de sus hermanos, pero cuando tienen tarea el también pues es más difícil." (Laura, 37 años, secundaria, ama de casa). Esta demanda ha generado en los últimos dos años un florecimiento inusitado de diversos locales que ofrecen sus servicios de renta de computadoras, acceso a Internet y realización de tareas escolares por encargo en el centro de Chalco. En la mayoría de los casos se trata de establecimientos improvisados y piratas, que se instalan con tres o cuatro computadoras en escritorios públicos, fotocopiadoras, papelerías, tiendas de abarrotes y casas de familia que disponen de la sala o el estacionamiento para ofrecer sus servicios[8]. A pesar de la fragmentación y el desorden de las búsquedas, el mal uso y aprovechamiento de los exploradores, la dudosa eficacia pedagógica del "cortar y pegar" por encargo, la informalidad y las fallas técnicas que padecen la mayoría de estos lugares, no podemos negar su importancia como fuente de socialización, iniciación y aprendizaje del manejo de la computadora e Internet entre los jóvenes de sectores populares: “... podría considerarse a los cibercafés como puntos de difusión de una innovación cultural profunda. Son lugares donde se permite el acceso, casi sin supervisión ni censura, a contenidos culturales ajenos, exóticos, eróticos, prohibidos y muy contrastantes con los códigos cotidianos de los usuarios jóvenes. Se puede juzgar a los cibercafés como instrumentos provocadores, catalizadores de la fragmentación de significados propios del posmodernismo, insertos en los ambientes premodernos (¿o modernos?) de los pueblos y las colonias de la periferia urbana, a donde han llegado recientemente migrantes atraídos por las dinámicas urbes del México contemporáneo" (Robinson, 2003: 2).

\section{El papel de los medios de comunicación como agentes socializadores de las nuevas tecnologías}

Por su parte, además de los hijos y la escuela, los medios de comunicación, particularmente la televisión, tienen un papel importante en el proceso de socialización y de representación acerca de los usos y funciones de las nuevas tecnologías. Las computadoras e Internet están presentes en las narrativas de los medios desde hace por lo menos 20 años, y su presencia se ha incrementado en la última década. La publicidad comercial y oficial, las películas, las telenovelas, los noticiarios, y los programas de divulgación científica, abordan de diversas formas el tema. Desde la perspectiva de los habitantes de San Lorenzo Chimalpa, estas múltiples narrativas sobre la computadora e Internet pueden agruparse en dos visiones, una benévola y otra maligna. La benévola sostiene las posibilidades infinitas del uso de la tecnología, una especie de varita mágica capaz de arreglar los problemas del mundo: “(...) ya se facilita todo, ya no se mortificarían por investigar, ya nada más es apretar botoncitos y te sale la información" (Ama de casa, 45 años, primaria). También incluye las ventajas en términos de educación y progreso, oportunidades de desarrollo, y comunicación asociado a su facilidad de comunicar rápida y simultáneamente a las personas ubicadas en comunidades alejadas, o a los que migraron con los que se quedaron, como en su momento fueron las carreteras y el teléfono. La otra idea, de signo contrario, habla de sus peligros y riesgos en términos de enajenación, pornografía, delincuencia, control, e invasión de la privacidad. Una de las imágenes que aparece en forma recurrente es la de la computadora como una especie de big brother, capaz de controlar la vida de las personas y de invadir los ámbitos más recónditos de la intimidad: "He visto en la tele que averiguan muchas cosas por la computadora, (...) saben su dirección,(...)saben el dinero, todo averiguan ahí(...). hasta los rateros de ahí sacan muchas cosas, mucha investigación para las personas." (Ama de casa, 40 años, primaria ), o como una máquina destructiva capaz de organizar "una guerra de botones" "...también ha avanzado para mal, yo siento que inclusive una guerra a futuro va a ser a base de botones, ya no se van a pelear, a base de botones se va a escribir el mundo" (Comerciante, secundaria, 70 años).

Sin embargo, el bombardeo de comerciales, películas y programas sobre el tema recién hace sentido de realidad cuando en el ámbito de lo local se empieza a instalar subjetivamente como algo 
socialmente necesario, y en el caso de San Lorenzo Chimalpa sin lugar a dudas lo que produjo este hecho fue la percepción de los posibles beneficios para la educación de los hijos. En los ejemplos que siguen es la demanda de la hija, vinculada a la escuela lo que permite focalizar la atención en lo que dice la televisión al respecto: "Cuando la anunciaron en la tele, la verdad en ese tiempo no le tomé interés, le empecé a tomar interés cuando mi hija me decía que sus amigas le platicaban que estaban en clases de computación y que ella quería ir también" (mujer, 28 años, secundaria, comerciante. "Pues en la tele cuando el gobierno anunció que las escuelas iban a tener computadoras para que los niños aprendieran, desde ahí me di cuenta que ya eran importantes las computadoras" (Juana, 52 años, primaria, ama de casa). En el segundo ejemplo, el anuncio del gobierno respecto a la escuela vuelve a la computadora social y culturalmente relevante, y también la ubica definitivamente en el imaginario como una extensión de la escuela que puede ser llevada a la casa, prolongando los efectos benéficos de la educación.

\section{El temor de que la computadora se convierta en un nuevo factor de exclusión social}

Detrás de la fuerte valoración de la computadora como una herramienta para acceder a recursos más calificados, y obtener empleos de mayor jerarquía y mejor remunerados, se esconde la otra cara de la misma moneda: la representación de la computadora como la responsable en el presente y en el futuro de la pérdida del empleo a partir de desplazar al hombre como fuerza de trabajo: "(...) (las computadoras) se crearon para suplantar al hombre y que ya no trabajen las personas, para que las empresas ya no tengan que pagar(...), vayan poco a poco liquidando personal y ya no pagar." (Martha, 39 años, primaria, obrera). En el imaginario popular la computadora es "humanizada" gracias a su capacidad tecnológica de reemplazar al hombre, al mismo tiempo que deshumaniza las habilidades manuales de los trabajadores al volverlas socialmente innecesarias para la producción: "Ya se está dando incluso en trabajos de fábricas automotrices que he visto que hay brazos que hacen labores que el hombre antes hacía o hace y es colocar muchas cosas, y ve en el tiempo que estamos, imagínate más adelante (Laurentino, 20 años, preparatoria, operador). El temor no es sólo a perder el empleo, o, a no encontrar empleo, sino a volverse socialmente innecesario y prescindible: “(...)habrían un montón de desempleados (...) empezarían a hacer a un lado a la gente y ya no la tomarían en cuenta por su capacidad que tiene" (mujer, 28 años, secundaria, ama de casa). Además, perciben, que esta amenaza también podría extenderse al lazo social. La computadora, al resolver las tareas de varios hombres, elimina la línea de producción, lo cual también afecta el engranaje colectivo donde unos dependen de los otros para terminar la pieza, creando lazos solidarios que se extienden más allá de la fábrica.

La valoración negativa y positiva acerca de las posibilidades de la computadora pueden convivir en el imaginario de los habitantes de San Lorenzo porque representan dos aspectos del mismo problema, expresan al mismo tiempo las expectativas y los temores que genera la aparición de una nueva tecnología de información resignificados, por una parte, a partir de la experiencia de viejas desigualdades en el acceso a los bienes culturales y de consumo, y, por otra, de nuevas amenazas de exclusión y marginación social. De ahí que en el imaginario popular, la necesidad de incorporar la computadora no surge tanto de percibir las posibilidades del mundo virtual, sino más bien de las carencias, necesidades y amenazas del mundo real. Y, en ese sentido, la representación de sus usos y potencialidades se expresa en el imaginario como un recurso compensatorio que permitiría superar o paliar las desventajas de la situación de pobreza.

\section{Para concluir}

En los sectores populares, la representación sobre los usos y posibilidades de la computadora se construye fundamentalmente sobre la base de la experiencia social de la desigualdad en el acceso a otros bienes culturales, donde muchas otras formas de "no tener acceso" contribuyen configurar el sentido primordial de esta nueva forma de no tener acceso[9]. Frente a esto se impone una visión instrumental de la computadora donde prevalece la idea de que en el futuro sólo los hombres y las mujeres que sepan manejar eficientemente una computadora serán capaces de progresar y de mejorar su situación socio-económica consiguiendo buenos empleos. Afirma Michel Autés, que la exclusión 
en los países europeos es "un imaginario de la caída social” (2004:24) vinculado a la precarización o a la pérdida del empleo; en nuestras realidades, dónde más del $40 \%$ de la población económicamente activa tiene trabajos eventuales, mal remunerados y sin ninguna clase de prestación y/o cobertura social, la exclusión se representa en el imaginario no como una amenaza de "la caída" en el presente, sino como el riesgo de "no poder levantarse en el futuro". Este temor aparece asociado al posible fracaso escolar de los hijos, que provocaría la no superación de la pobreza y la reproducción de la situación de marginación de los padres.

Es bastante probable que, por una parte, el temor de que la computadora se convierta en un nuevo factor de exclusión y diferenciación social, y por otra, la expectativa de que ésta asociada a la educación pueda provocar un aceleramiento del proceso de movilidad social, impulsen en los próximos años una fuerte reorientación en las prioridades del consumo y una reorganización del espacio doméstico en los sectores populares ubicados en áreas urbano-marginales para incorporar la computadora e Internet. El riesgo de esta apreciación, es que se imponga una visión meramente instrumental de la computadora, donde en lugar de ser vista como un recurso que amplia las posibilidades de acceso a la información y al intercambio de experiencias a nivel local, regional y global asociadas al capital escolar, se convierta ilusoriamente en un gran atajo que tienda a reemplazar los largos y costosos ciclos de la educación tradicional por cursos de entrenamiento operativo, empobreciendo el capital cultural y reforzando las inequidades ya existentes.

El imaginario sobre las posibilidades y usos de Internet se construye por la confluencia de tres agentes de mucho peso en la vida cotidiana: la escuela, los medios de comunicación y las redes familiares. En el primer caso, por la presión que ejerce la escuela reforzando necesidades simbólicas vinculadas a las expectativas de movilidad social. En el segundo caso, sobre la base de la apropiación selectiva de los relatos e imágenes que circulan en la televisión, particularmente en las telenovelas, las películas, y la propaganda comercial. Lo cual nos habla de la importancia de estudiar los usos y sentidos de esta tecnología en relación con otras tecnologías mediáticas presentes en el hogar. Y, por último, a partir de la socialización que hacen los usuarios con su amigos y familiares. Estos usuarios, generalmente jóvenes inscritos en algún sistema escolarizado, son los principales responsables de haber vuelto a la computadora socialmente necesaria en el imaginario de los pobres. A partir de las necesidades creadas por la escuela y sus pares, se convierten en una gran fuente de difusión y socialización del universo simbólico de Internet entre sus familiares, amigos, y vecinos, tendiendo puentes, traduciendo y socializando sus posibilidades y códigos de acceso. Sin embargo, como bien lo perciben las personas mayores de baja escolaridad en nuestro estudio, la posibilidad de comprar una computadora a plazos o mediante una estrategia de ahorros, no resuelve la cuestión del acceso. El mundo de la desigualdad informática no puede explicarse sólo a partir de la división entre los que tienen acceso a las nuevas tecnologías y entre los que no lo tienen, el problema es más complejo. La denominada brecha digital está múltiplemente conformada y segmentada por inequidades de diferente tipo. Como bien lo ha demostrado Castells (2001:275-299), la brecha digital no sólo se construye a partir de las diferencias socio-económicas, sino, también, de diferencias étnicas, generacionales, de género, y de capital cultural. A lo cual también agregaríamos otra de carácter simbólico entre quienes comprenden y se apropian de sus ventajas y potencialidades, y, entre quienes la perciben como un artefacto cuasi mágico que ilusoriamente podría evitarles una nueva clase de exclusión social que cada día se percibe como más amenazante: "Es de temer que hoy, en la construcción planetaria del nuevo entorno de redes (...) no disminuyan los 'sacrificados', con el agravante de la invisibilidad con que los encubre una tecnología blanda y productora, para colmo, de 'realidad virtual': la ficción simulativa puede convertirse en el mejor aliado de una realidad injusta" (Pérez Tapias, 2003:69).

Ya es prácticamente un lugar común afirmar que la brecha digital entre "inforicos" e "infopobres" no se resuelve repartiendo a granel computadoras en todas las escuelas donde asisten los marginados (y no sólo, ni fundamentalmente de las nuevas tecnologías). Como bien lo expresa Silverstone, “...las tecnologías no son creativas por sí mismas. (...) La tecnología sólo puede complementar y mejorar la vida social y cultural cuando ya hay algo de valor para complementar y mejorar" (2001:240). Al parecer, los que están en mejores condiciones de aprovechar las posibilidades de creación y 
comunicación en Internet no son todos los que tienen acceso a una computadora (condición necesaria pero no suficiente), sino los que poseen un capital informacional. Siguiendo a Bourdieu, Hamelink (1999:15) define este concepto como "la capacidad financiera para pagar la utilización de redes electrónicas y servicios de información, la habilidad técnica para manejar las infraestructuras de estas redes, la capacidad intelectual para filtrar y evaluar información y la habilidad de aplicar información a situaciones sociales". El otro problema que no se soluciona sembrando computadoras por doquier, es el de que las poblaciones más aisladas y/o marginadas social y/o geográficamente, reconozcan en las nuevas tecnologías una ventaja de "desarrollo", cuando no pueden advertir en los términos prácticos de su vida cotidiana ninguna ventaja para mejorar sus condiciones de existencia[10]. Si la computadora no puede volverse socialmente necesaria en la subjetividad colectiva de diversas comunidades rurales y urbanas, difícilmente los pobladores se sumen con entusiasmo a cualquier proyecto ciberalfabetizador: “(...) la mayoría de iniciativas estudiadas están divorciadas de la cultura local y han sido instrumentalizadas y adaptadas a las formas de ejercicio de poder tradicionales; una situación que se refleja en el abismo existente entre escuela y realidad local, entre las pedagogías vigentes y las necesidades de la comunidad" (Bonilla y Cliche, 2001, 606).

Las potencialidades de las nuevas tecnologías de información, dependen fundamentalmente de la generación de ambientes de socialización informática que reconozcan las particularidades y diferencias socio-culturales a nivel local y regional. Sin lugar a dudas, la escuela es la institución más indicada para implementar un conjunto de acciones al respecto, pero también habría que recuperar y orientar el papel que están jugando los denominados cafés Internet que se han constituido en iniciadores y socializadores naturales entre los adolescentes y jóvenes.

Por último, consideramos que la conformación de los imaginarios populares sobre las nuevas tecnologías de la información, se ha convertido en una cuestión de importancia socio-antropológica indiscutible. Este imaginario, al igual que sucedió con otras tecnologías mediáticas en su momento, organiza y reorganiza los sentidos, las expectativas y las demandas de las personas acerca de los usos de la tecnología en la intersubjetividad colectiva, donde se combinan sentidos y representaciones de diversos universos simbólicos a nivel social e individual[11]. Lo cual no sólo impacta las prioridades del consumo, la relación con el conocimiento, las formas de inclusión y exclusión social, las redes de sociabilidad y los estilos de vida, sino, también, los discursos políticos, las políticas públicas y las estrategias de visibilidad en la esfera pública.

\section{Bibliografía citada}

Arredondo, Miguel Angel, et al (2001) "Aproximación etnográfica a la introducción de nuevas tecnologías de información y comunicación en dos escuelas rurales del centro sur de Chile", en Marcelo Bonilla y Gilles Cliche, (editores) Internet y Sociedad en América Latina y el Caribe. FLACSO Ecuador/IDRC.

Auté Michel (2004) “Tres formas de desligadura” en Saül Karsz (coord.) La exclusión: bordeando sus fronteras. Definiciones y matices. Gedisa , Barcelona.

Bonilla Marcelo y Cliche Pilles (1998) "Introducción”, en Marcelo Bonilla y Gilles Cliche, (editores) Internet y Sociedad en América Latina y el Caribe. FLACSO Ecuador/IDRC.

Bourdieu, Pierre (1988) La distinción. Taurus, Barcelona.

Cabrera Paz, José (2001) "Náufragos y navegantes en territorios hipermediales: experiencias psicosociales y prácticas culturales en la apropiación del Internet en jóvenes escolares", Marcelo Bonilla y Gilles Cliche (editores) Internet y Sociedad en América Latina y el Caribe. FLACSO Ecuador/IDRC.

Castells, Manuel (2001) La galaxia Internet, Editorial Arete, Madrid. 
Ford, Anibal (1999) La marca de la bestia. Identificación, desigualdades e infoentretenimiento en la sociedad contemporánea, Editorial Norma, Buenos Aires.

Hamelink, Cees J. (1999) "Language and the right to comunicate", Media Development, Vol. XLVI, 4/1999, London, WACC.

Jodelet, Denise (1984) "La representación social: fenómenos, conceptos y teoría", en S. Moscovici, Psicología Social II. Pensamiento y vida social. Psicología social y problemas sociales., Paidós, Barcelona.

León Osvaldo, et al (2001) Movimientos sociales en la red. ALAI, Quito.

O’Sullivan, et.al. (1997) Conceptos claves en comunicación y estudios culturales. Amorrortu editores, Buenos Aires.

Perez Tapias, José Antonio (2003) Internautas y Náufragos. La búsqueda del sentido en la cultura digital, Editorial Trotta, Madrid.

Silverstone, Roger (2004) ¿Por qué estudiar los medios?, Amorrortu Editores, Buenos Aires.

Robinson, Scott (2003) "Los retos culturales de los cibercafés: Los changarros olvidados”, Ponencia presentada en el Seminario organizado por el CRIM: Cultura e Internet, Cuernavaca.

Zancheti Edgardo y Cappelechio Leandro (2003) "Programa argentin@internet.todos: Programa prioritario de investigación Aldea 21", En.red.ando, Revista Electrónica. www.enredando.com.

\section{Notas:}

[1] Publicado originalmente en la revista Educar, se reproduce por autorización expresa de la autora.

[2] Fuente: INEGI. Encuesta Módulo Nacional de Computación, 2001.

[3] Fuente: Unicef y Microsoft México. Citado por La Jornada, pag. 54, 29 /05/03.

[4] Esta investigación se llevó a cabo en el año 2003 con la participación de los alumnos del proyecto de investigación y servicio social: "Redes virtuales y comunidades mediáticas. Nuevos núcleos de sociabilidad y pertenencia". San Lorenzo Chimalpa es un pequeño poblado donde habitan alrededor de 150 familias en una extensión de 10 manzanas. A pesar de estar ubicado a 20 minutos del Centro de Chalco, un municipio de alta densidad poblacional en la periferia de la ciudad de México, San Lorenzo conserva rasgos semi rurales. Muchos de sus habitantes son campesinos que trabajan su propia milpa o la de algún vecino. En San Lorenzo los vecinos desarrollan una intensa vida comunitaria que gira alrededor de la iglesia, el mercado y las celebraciones familiares. No obstante, existe una relación de intercambio permanente y fluída con el Centro de Chalco y la Ciudad de México. La mayoría de los pobladores, particularmente los jóvenes, se desplazan a trabajar, ir de compras o estudiar al centro de Chalco o al Distrito Federal. También es habitual que las familias vayan de compras, al cine o a comer los fines de semana o feriados. La mayoría de los padres y madres de familia de más de 30 años cuentan sólo con la primaria o secundaria, sin embargo es evidente la aspiración de que sus hijos superen esa situación, y las familias hacen grandes esfuerzos económicos para que sus hijos lleguen a la universidad. La mayoría de los niños, adolescentes y jóvenes se encuentran estudiando en algún sistema escolarizado.

[5] El 66.5\% de los pobres considera que la situación económica de sus hijos y/o nietos será mucho mejor que en el presente. Fuente: Encuesta Lo que dicen los pobres, SEDESOL, julio de 2003. (datos citados por Miguel Székely...... ) 
[6] Una investigación desarrollada en Chile sobre la introducción de nuevas tecnología de información y comunicación en dos escuelas rurales de Chile, muestra resultados coincidentes con la nuestra, respecto a cómo el imaginario sobre la educación como estrategia de movilidad social se conecta con el acceso a la computadora (Arredondo, 2001:131).

[7] Se trata de familias donde el padre o la madre poseen educación universitaria.

[8] Aunque la mayoría de los habitantes de San Lorenzo Chimalpa se trasladan al Centro de Chalco, distante a unos veinte minutos, en el poblado ya existen dos, uno dentro de una papelería y otro en una tienda de abarrotes.

[9] Es interesante señalar como la palabra acceso se ha instalado en el imaginario popular como un término que atribuye más significado a la falta que a la posesión de algo en relación con el capital cultural y las tecnologías mediáticas: "La cuestión es tener o no tener acceso a los medios. De modo tal que el lector lo encontrará con mucha más frecuencia formando parte de reclamos que en análisis del acceso mismo" O’Sullivan, et.al., 1997:17)

[10] En el caso del Programa argentin@internet.todos: Programa prioritario de investigación Aldea 21 , los resultados de la evaluación del año 2001 y 2002 ,indicaron que la mayoría de los Centros Tecnológicos Comunitarios (CTC) se encontraban en una fase elemental de aprovechamiento de las potencialidades de la red. Se señalan varias causas que explican el bajo rendimiento del programa, entre ellas destacan, según manifestaron los beneficiarios del programa, “ (...) la falta de una visión de utilidad de Internet para sus necesidades cotidianas" (Zancheti y Cappelechio, 2003:3)

[11] Dan Andasko define el imaginario tecnológico como: “...el entramado de imágenes e ideas que el hombre se hace acerca de la tecnología y de su vínculo con ella; un conjunto de representaciones que conforma un determinado orden y da sentido a la relación del hombre con el resto de la sociedad y con el universo que lo rodea. Asimismo el imaginario tecnológico conlleva una cosmovisión del mundo.”(1998:61). 